\title{
Effects of cis-9,trans-11 and trans-10,cis-12 Conjugated Linoleic Acid, Linoleic Acid, Phytanic Acid and the Combination of Various Fatty Acids on Proliferation and Cytokine Expression of Bovine Peripheral Blood Mononuclear Cells
}

\section{Lydia Renner $^{1}$, Susanne Kersten ${ }^{1, *}$, Anna Duevel ${ }^{2}$, Hans-Joachim Schuberth ${ }^{2}$ and Sven Dänicke ${ }^{1}$}

1 Institute of Animal Nutrition, Friedrich-Loeffler-Institute (FLI), Federal Research Institute for Animal Health, Bundesallee 50, 38116 Braunschweig, Germany;

E-Mails: lydia.renner@googlemail.com (L.R.); sven.daenicke@fli.bund.de (S.D.)

2 Immunology Unit, University of Veterinary Medicine, Bischofsholer Damm 15, 30173 Hannover, Germany; E-Mails: anna.mareike.duevel@tiho-hannover.de (A.D.); hans-joachim.schuberth@tiho-hannover.de (H.-J.S.)

* Author to whom correspondence should be addressed; E-Mail: susanne.kersten@fli.bund.de; Tel.: +49-531-596-3152; Fax: +49-531-596-3199.

Received: 8 April 2013; in revised form: 31 May 2013 / Accepted: 24 June 2013 /

Published: 12 July 2013

\begin{abstract}
Fatty acids may have an impact on immune functions, which is important in times of increased mobilization of body fat, e.g., around parturition. The aim of the present study was to investigate the effects of the CLA isomers cis-9,trans-11 and trans-10,cis-12, phytanic acid (PA), linoleic acid (LA) and a fatty acid (FA) mixture (containing 29.8\% palmitic acid, $6.7 \%$ palmitoleic acid, $17.4 \%$ stearic acid and $46.1 \%$ oleic acid) on the proliferation of bovine blood mononuclear cells (PBMC) in vitro using alamar blue (AB) and 5-bromo-2'-deoxyuridine (BrdU) assay. Quantitative real time polymerase chain reaction analyses were performed to evaluate the expression of interleukin (IL)-4, IL-10, interferon (IFN)- $\gamma$, tumor necrosis factor (TNF)- $\alpha$ and peroxisome proliferator-activated receptor (PPAR)- $\gamma$ in response to cis-9,trans-11 and LA. The $\mathrm{IC}_{50}$ values did not differ between the investigated FA, but there were differences within the proliferation in the response of these $\mathrm{FA}$ in a concentration range between 20 and $148 \mu \mathrm{M}$ (e.g., increased proliferation after treatment with lower concentrations of LA). No differences occurred when different FA combinations were tested. ConA stimulation increased the expression of TNF- $\alpha$ and IFN- $\gamma$, whereas IL-10 decreased. In general, neither the baseline expression nor
\end{abstract}


the ConA-stimulated mRNA expression of cytokines and PPAR- $\gamma$ were affected by the FA. In conclusion, all FA inhibit the proliferation of PBMC dose dependently without significantly altering the induced cytokine spectrum of activated bovine PBMC.

Keywords: conjugated linoleic acid; phytanic acid; bovine peripheral blood mononuclear cells; proliferation; cytokine expression

\section{Introduction}

Conjugated linoleic acids (CLA) are positional isomers of the C18:2 fatty acid (FA) linoleic acid. They are characterized by the conjugated position of their double bonds. They occur predominantly in ruminants, because CLA, and especially the cis-9,trans-11 isomer, are intermediate products of the biohydrogenation of unsaturated fatty acids by ruminal microorganisms [1,2]. The proportion of cis-9,trans-11 CLA in the serum is rather low (0.02 g/100 g total FA), but increased 10 fold due to feeding fresh pasture [3]. An alternative pathway to form CLA is via endogenous synthesis by $\Delta$ 9-desaturase and trans-11 C18:1 as a precursor [4], which is also observed in non-ruminants like humans [5]. Although CLA is formed in ruminants (especially the cis-9,trans-11 isomer), the supplementation of dairy cows with CLA gains in importance because of its milk fat reducing effect which is mainly ascribed to the trans-10,cis-12 isomer [6]. However, information on immune modulating effects of CLA in dairy cows and bovine cells are scarce. Feeding a CLA mixture to dairy cows had no effect on the mitogen-stimulated proliferation of peripheral blood mononuclear cells (PBMC) ex vivo [7], but the proliferation of splenocytes was decreased in the CLA-fed group 105 days post partum [8]. In the latter study, the effects on cytokine expression were rather conflicting. In these studies a mixture of different CLA isomers was used (mainly cis-9,trans-11 and trans-10,cis-12). The impact of different CLA isomers on the proliferation of bovine PBMC has not yet been investigated.

Another potential bioactive fatty acid is the C20 branched chain FA phytanic acid (PA, 3,7,11,15-tetramethylhexadecanoic acid) [9]. PA originates from phytol, a side chain of chlorophyll, which is released from chlorophyll by ruminal microorganisms and converted into PA [10,11]. The concentration of PA in serum of cows is indicated as $5.9 \mathrm{mg} / \mathrm{mL}(=188.8 \mu \mathrm{M})$ by Avigan [12]. Thompson et al. [13] investigated the concentration of PA in triazylglyceroles of arterial and venous plasma of cows and reported $6.2 \mu \mathrm{M}$ in arterial and $6.0 \mu \mathrm{M}$ in venous plasma. The average PA plasma concentration in male subjects from Germany was $2.91 \mu \mathrm{M}$ (results from the EPIC study [14]). PA does not undergo direct $\beta$-oxidation. It is degraded to pristanic acid by $\alpha$-oxidation $[10,15]$. A lack of the first enzyme of $\alpha$-oxidation is associated with increased levels of PA in plasma and tissues. This rare inherited dysfunction is called Refsum's disease and shows the following clinical signs: pigmentary retinal degeneration, peripheral neuropathy, cerebellar ataxia and high concentrations of protein in the cerebrospinal fluid [9,10]. It is reported that PA serves as a ligand of retinoid X receptor (RXR) [16] and peroxisome proliferator-activated receptor (PPAR)- $\alpha$ [17]. Therefore, it is considered as beneficial in prevention of type-2 diabetes and metabolic syndrome [9]. Because both FA share similar activation mechanisms, both are ligands of PPARs [18], there are probably complementary interactions in their anti-diabetic activity [19]. Hence, it is hypothesized that CLA and PA share 
effects on bovine immune cells. Therefore, in vitro studies were performed investigating different FA-including CLA and PA-in various concentrations and combinations. The focus of the research was on the effect of these FA on the proliferation of bovine PBMC. Furthermore, effects on the expression of cytokines were tested for selected FA.

\section{Experimental Section}

If not stated otherwise chemicals were purchased from Sigma-Aldrich, Steinheim, Germany.

\subsection{Sample Preparation}

PBMC were obtained from the blood of three different cows. The animals were chosen according to their age, lactation number and lactation stage. All three cows were in their second lactation. The blood samples were taken at two points in time (between 59 and 116 days in milk and 116 and 173 days in milk, respectively) by venipuncture of the vena jugularis externa using heparinized vacutainer tubes to obtain PBMC. PBMC were prepared following the procedure described by Renner et al. [20]. The samples were frozen and stored at $-80{ }^{\circ} \mathrm{C}$ until cell proliferation assays were performed. The concanavalin A (ConA) stimulated $(2.5 \mu \mathrm{g} / \mathrm{mL})$ cell proliferation was analyzed using alamar blue (AB) and BrdU (5-bromo-2'-deoxyuridine) assay. In the $\mathrm{AB}$ assay, a nonfluorescent dye is reduced by metabolically active cells. The resulting dye resorufin fluoresces [21]. The BrdU assay is based on the incorporation of the pyrimidine analogue BrdU instead of thymidine into the DNA of proliferating cells.

FA were diluted in dimethyl sulfoxide (DMSO, D 2438) to obtain a stock solution (250 mM) and dose response studies were performed with various FA: linoleic acid cis-9, cis-12 C18-2 (L 1012), cis-9,trans-11 CLA (Matreya, Pleasant Gap, PA, 1245), trans-10,cis-12 CLA (Matreya, Pleasant Gap, PA, 1249), and a mixture of FA to mimic the FA composition of the subcutaneous adipose tissue according to Rukkwamsuk et al. [22]. The FA mixture contained 29.8\% palmitic acid C16:0 (P 0500), 6.7\% palmitoleic acid cis-9 C16:1 (P 9417), 17.4\% stearic acid C18:0 (85679), and 46.1\% oleic acid cis-9 C18:1 (O 1383). Furthermore, a dose response study was performed with the branched chain FA phytanic acid (P 4060). The experiments were conducted with FA concentrations between 0 and $500 \mu \mathrm{M}$ and 1:1.5 dilution steps. Additionally, the effect of the vehicle (0.2\% DMSO) was tested at each setting (stated as $0 \mu \mathrm{M}$ ).

The goal of the dose-response studies was to determine reasonable concentrations for further experiments, in which the effect of a combination of different FA on the proliferation of bovine PBMC was investigated. The following FA combinations were tested at 33, 66, 99 and $500 \mu \mathrm{M}: 60 \%$ FA mixture and $40 \%$ of LA, cis-9,trans-11, trans-10,cis-12 CLA or $13.3 \%$ of each FA. The combination of $60 \%$ FA mixture and $40 \%$ PA or $20 \%$ PA and $20 \%$ cis-9,trans-11 and trans-10,cis-12, respectively was analyzed at 33, 66, 99, 150 and $500 \mu \mathrm{M}$. Each setting contained a vehicle control (0.2\% DMSO) and a medium control (only medium without DMSO and FA).

\subsection{Cell Culture Conditions and Cell Proliferation Assays}

Frozen PBMC were thawed and washed with Roswell Park Memorial Institute (RPMI)-1640 medium (Biochrom AG, Berlin, Germany, F 1295) supplemented with 5\% fetal bovine serum (FBS, 
Biochrom AG, S 0615), 1 M HEPES (4-(2-hydroxyethyl)-1-piperazineethanesulfonic acid) buffer (Biochrom AG, L 1603), 2 mM L-glutamine (Biochrom AG, K 0282), 5 mM $\beta$-mercaptoethanol (M 7522), $100 \mathrm{U} / \mathrm{mL}$ penicillin and $0.1 \mathrm{mg} / \mathrm{mL}$ streptomycin (Biochrom AG, A 2212) and a second time with phosphate buffered saline (PBS, Biochrom AG, L 1820). The samples were centrifuged at $250 \times g$ for $8 \mathrm{~min}$ at room temperature. Supernatants were discarded. After the second washing step, the pellet was suspended in a supplemented RPMI-1640 medium, and cells were adjusted to $1 \times 10^{6}$ cells/mL using the trypan blue exclusion technique and a Neubauer counting chamber. PBMC were seeded into 96-well plates $\left(1 \times 10^{5}\right.$ cells/well), the FA solution and ConA $(2.5 \mu \mathrm{g} / \mathrm{mL}$ final, C 5275) or RPMI-1640 medium were added up to a final volume of $200 \mu \mathrm{L} /$ well. Each set up was performed in 4 replicates. The plates were incubated for $72 \mathrm{~h}$ at $37{ }^{\circ} \mathrm{C}$ and $5 \% \mathrm{CO}_{2}$. After incubation, the plates were centrifuged at $200 \times g$ for $5 \mathrm{~min}$ and $100 \mu \mathrm{L}$ of the supernatant per well were removed. The ConA concentration and the used incubation time is based on the study of Goyarts et al. [23].

Subsequently, $\mathrm{AB}$, evaluating metabolic activity, and BrdU assays, evaluating DNA synthesis, were performed as indicators for ConA stimulated PBMC proliferation. AB (AbDSerotec, Oxford, UK, BUF012A) was added (1:10 final) and incubated for another $2.5 \mathrm{~h}$. The fluorescence of the $\mathrm{AB}$ reduction product resorufin was measured at $540 \mathrm{~nm}$ (excitation) and $590 \mathrm{~nm}$ (emission).

The BrdU proliferation kit (Roche Diagnostic GmbH, Mannheim, Germany, 11647229 001) was used according to manufacturer's instructions.

\subsection{RNA Isolation and $c D N A$ Synthesis}

The FA and their concentrations used for cytokine expression studies were selected based on the results of the cell proliferation assays. PBMC were incubated as described above. Set ups were done in 8 replicates (later pooled for RNA isolation). AB assays were performed as a control in parallel. The RNeasy Mini Kit (Qiagen GmbH, Hilden, Germany; 74104) was used for RNA isolation following the manufacturer's protocol. The RNA quantity was analyzed spectrophometrically at $260 \mathrm{~nm}$ (Nanodrop).

For cDNA synthesis the SuperScript ${ }^{\mathrm{TM}}$ II Reverse Transcriptase kit and oligo(dT) $)_{12-18}$ primer (both from Invitrogen by Life Technologies, Darmstadt, Germany 18418012) were used according to manufacturer's instructions.

\subsection{Quantitative Real Time PCR}

The PCR was performed using SYBER green master mix (Invitrogen 4364344). Analyses were carried out in duplicates. Each reaction contained $24 \mu \mathrm{L}$ reaction mix and $1 \mu \mathrm{L}$ cDNA or water as negative control. The reaction mix contained SYBR Green ${ }^{\circledR}$ PCR master mix, RNAse-DNAse-free water and forward and reverse primer (sequences and concentrations presented in Table 1) in proportions specific for the gene of interest. The reaction started with heating up to $95{ }^{\circ} \mathrm{C}$ to denaturate the DNA. Subsequently 40 cycles of denaturation at $95{ }^{\circ} \mathrm{C}$ for $15 \mathrm{~s}$ and annealing of primers and elongation of the product for $1 \mathrm{~min}$ at $60{ }^{\circ} \mathrm{C}$ were performed. Afterwards the products were heated from 60 to $95{ }^{\circ} \mathrm{C}$ in $0.3{ }^{\circ} \mathrm{C}$ steps to obtain a melting curve. The PCR products were quantified by a standard series of cDNA subclones with at least 5 points $\left(10^{2}-10^{6}\right.$ copies $)$ analyzed simultaneously to the samples. 
Table 1. Primer sequences and concentrations used for real-time PCR analysis.

\begin{tabular}{|c|c|c|c|c|}
\hline Gene & $\begin{array}{c}\text { Forward (for) and reverse (rev) primer } \\
\text { sequences }\left(5^{\prime} \rightarrow 3^{\prime}\right)\end{array}$ & $\begin{array}{c}\text { concentration } \\
(\mathbf{n M})\end{array}$ & Bp ${ }^{\text {a }}$ & Reference \\
\hline \multirow{2}{*}{ IL-4 } & for GCC ACA CGT GCT TGA ACA AA & 900 & \multirow{2}{*}{63} & \multirow{2}{*}[24]{} \\
\hline & rev TGC TTG CCA AGC TGT TGA GA & 50 & & \\
\hline \multirow{2}{*}{ IL-10 } & for CCT TGT CGG AAA TGA TCC AGT TTT & 300 & \multirow{2}{*}{67} & \multirow{2}{*}[24]{} \\
\hline & rev TCA GGC CCG TGG TTC TCA & 300 & & \\
\hline \multirow{3}{*}{ IL-12 } & for TGG TCG TTT CCT GGT TTT CC & 300 & \multirow{3}{*}{205} & novel design \\
\hline & rev GTT TTG CCA GAG CCC AAG AC & 300 & & (Accession \\
\hline & & & & No. NM 174356.1) \\
\hline \multirow{2}{*}{ INF- $\gamma$} & for TTC AGA GCC AAA TTG TCT CCT TC & 300 & \multirow{2}{*}{205} & \multirow{2}{*}{ [25] modified form } \\
\hline & rev AGT TCA TTT ATG GCT TTG CGC TG & 50 & & \\
\hline \multirow{2}{*}{ TNF- $\alpha$} & for CTT CTG CCT GCT GCA CTT CG & 300 & \multirow{2}{*}{156} & \multirow{2}{*}[26]{} \\
\hline & rev GAG TTG ATG TCG GCT ACA ACG & 300 & & \\
\hline \multirow{2}{*}{ PPAR- $\gamma$} & for AAG AAT ATC CCC GGC TTT GT & 300 & \multirow{2}{*}{200} & novel design \\
\hline & rev TTG GGC TCC ATA AAG TCA CC & 300 & & $\begin{array}{c}\text { (Accession } \\
\text { No. NM 181024) }\end{array}$ \\
\hline
\end{tabular}

${ }^{\mathrm{a}}$ bp length of amplicons in base pair.

\subsection{Calculations and Statistics}

The stimulation index $(S I)$ in the $\mathrm{AB}$ assay was calculated by the following equation:

$$
S I=\frac{\text { Fluorescence or OD of ConA stimulated PBMC }}{\text { Fluorescence or OD of nonstimulated PBMC }}
$$

The dose response curves (SI) were fitted to the following nonlinear regression equation [27]:

$$
S I=\frac{R_{0} \cdot K_{05}{ }^{b}+R_{\max } \cdot \operatorname{Con}^{b}}{K_{05}^{b}+\operatorname{Con}^{b}}
$$

where: $R_{0}=$ intercept on ordinate (SI at $0 \mu \mathrm{M}$ ), $R_{\max }=$ asymptotic $S I$ when Con converges to infinity, Con $=$ FA concentration $(\mu \mathrm{M}), K_{05}=S I$ at $0.5 \times\left(R_{\max }+R_{0}\right), b=$ apparent kinetic order. According to mean values of all separate curves (fatty acids and animals) $R_{0}$ and $R_{\max }$ were defined for all variants. The SI was only calculated for the AB assay, because non-stimulated PBMC did not proliferate and therefore showed weak signals.

The proliferation of the ConA stimulated PBMC was calculated in relation to the control (no FA, but with DMSO), which was set at $100 \%$ in the $\mathrm{AB}$ and BrdU assay. For the BrdU assay, the proliferation of each FA was fitted to the following nonlinear regression equation:

$$
\operatorname{Resp}=\frac{100-R_{\max }}{\left(1+a^{b \cdot C o n}+c^{d \cdot \operatorname{Con}}-a-c\right)+R_{\max }}
$$

where Resp = proliferation (\%), $R_{\max }=$ asymptotic proliferation when Con converges to infinity, Con = FA concentration $(\mu \mathrm{M}) a, b, c, d=$ other estimation parameters. The resulting curves from Equations (1) and (2) were used to estimate the $\mathrm{IC}_{50}$ value of the investigated FA. 
A one factorial ANOVA was performed within the $\mathrm{IC}_{50}$ values of the $\mathrm{AB}$ assay and the results of mRNA expression analyses. A multifactorial ANOVA was used for analyses of the ConA stimulated proliferation (\% of control) of BrdU and $\mathrm{AB}$ assay, where the FA and FA concentrations are fixed factors. In addition, interactions between these factors were calculated. The Tukey test was used as a post-hoc test.

All statistical analyses were calculated using the Statistica for the Windows operating system.

Figure 1. Effects of a fatty acid mixture* ( $\square)$, linoleic acid ( $\square)$, cis-9,trans-11 ( $\square$ ), trans-10,cis-12 ( $\square$ ) and phytanic acid $(\square)$ on concanavalin A stimulated proliferation of bovine peripheral blood mononuclear cells $(n=3)$ in the alamar blue assay (means \pm standard deviation). * containing 29.8\% palmitic acid, 6.7\% palmitoleic acid, $17.4 \%$ stearic acid and $46.1 \%$ oleic acid according to Rukkwamsuk et al. [22]. a-d: different letters indicate significant differences within the same fatty acid, *, \#, \$ indicate significant differences between fatty acids at the same concentration, $p<0.05$, Tukey test.

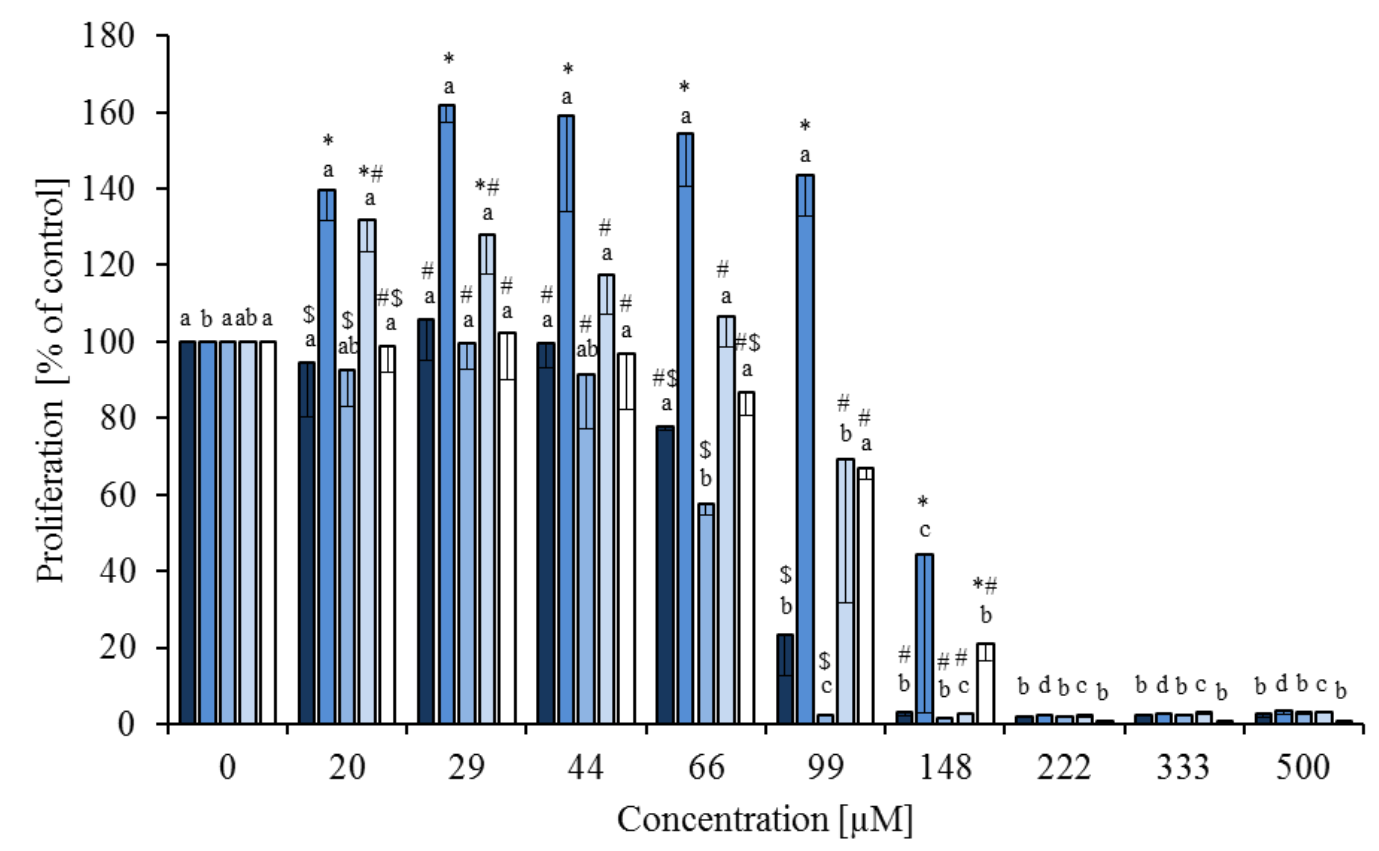

\section{Results}

\subsection{Dose Response Studies}

The dose response curves (based on the $S I$ obtained in the $A B$ assays) were fitted to equation 2 and used to calculate $\mathrm{IC}_{50}$ values. The $\mathrm{IC}_{50}$ values (means $\pm \mathrm{SD}$ ) were as follows: LA $100.7 \pm 18.4 \mu \mathrm{M}$, cis-9,trans-11 $53.8 \pm 11.9 \mu \mathrm{M}$, trans-10,cis-12 $70.1 \pm 12.5 \mu \mathrm{M}$, PA $94.7 \pm 29.8 \mu \mathrm{M}$ and the FA mixture $80.8 \pm 21.4 \mu \mathrm{M}$. Differences between FA IC 50 values were not significant $(p=0.093)$. For further cytokine expression analyses the FA with the lowest (cis-9,trans-11) and the highest (LA) IC50 value were used. Considering the ConA-stimulated proliferation (defined as \% of control, without FA), there was an effect of FA, FA concentration and an interaction of these factors (always $p<0.01$ ) on PBMC proliferation, in the AB assay (Figure 1). The proliferation decreased significantly compared to control starting at $99 \mu \mathrm{M}$ for the FA mixture, $66 \mu \mathrm{M}$ for cis-9,trans-11, $148 \mu \mathrm{M}$ for trans-10,cis-12 
and PA. For LA, the proliferation increased from 20 to $99 \mu \mathrm{M}$ compared to control and decreased at concentrations $\geq 148 \mu \mathrm{M}$. An effect of the FA was seen between 20 and $148 \mu \mathrm{M}$, LA showed a higher proliferation than the remaining four FA.

In the BrdU assay there was also an effect of the FA, the FA concentration and an interaction of these factors (always $p<0.01$ ) on ConA-stimulated proliferation. The proliferation (shown as \% of control) decreased starting at $66 \mu \mathrm{M}$ for the FA mixture and cis-9,trans-11, at $99 \mu \mathrm{M}$ for trans-10,cis-12 and $148 \mu \mathrm{M}$ for LA and PA. Differences between the FA occurred between 44 and $99 \mu \mathrm{M}$ (Figure 2). The $\mathrm{IC}_{50}$ values obtained from dose-response curves (fitted to Equation (3)) were in the same range as those after $\mathrm{AB}$ assays: FA mixture $(71.2 \mu \mathrm{M})$, LA (104.4 $\mu \mathrm{M})$, cis-9,trans-11 $(57.5 \mu \mathrm{M})$. The $\mathrm{IC}_{50}$ value of trans-10,cis-12 isomer obtained with the BrdU assay was lower $(84.4 \mu \mathrm{M})$ and for PA higher $(115.1 \mu \mathrm{M})$ compared to IC $_{50}$ values obtained after AB assays.

Figure 2. Effects of a fatty acid mixture* ( $\square)$, linoleic acid ( $\square)$, cis-9,trans-11 ( $\square$ ), trans-10,cis-12 $(\square)$ and phytanic acid $(\square)$ on concanavalin A stimulated proliferation of bovine peripheral blood mononuclear cells $(n=3)$ in the BrdU assay (means \pm standard deviation). * containing $29.8 \%$ palmitic acid, $6.7 \%$ palmitoleic acid, $17.4 \%$ stearic acid and 46.1\% oleic acid according to Rukkwamsuk et al. [22]. a-c: different letters indicate significant differences within the same fatty acid, *, \#, \$ indicate significant differences between fatty acids at the same concentration, $p<0.05$, Tukey test

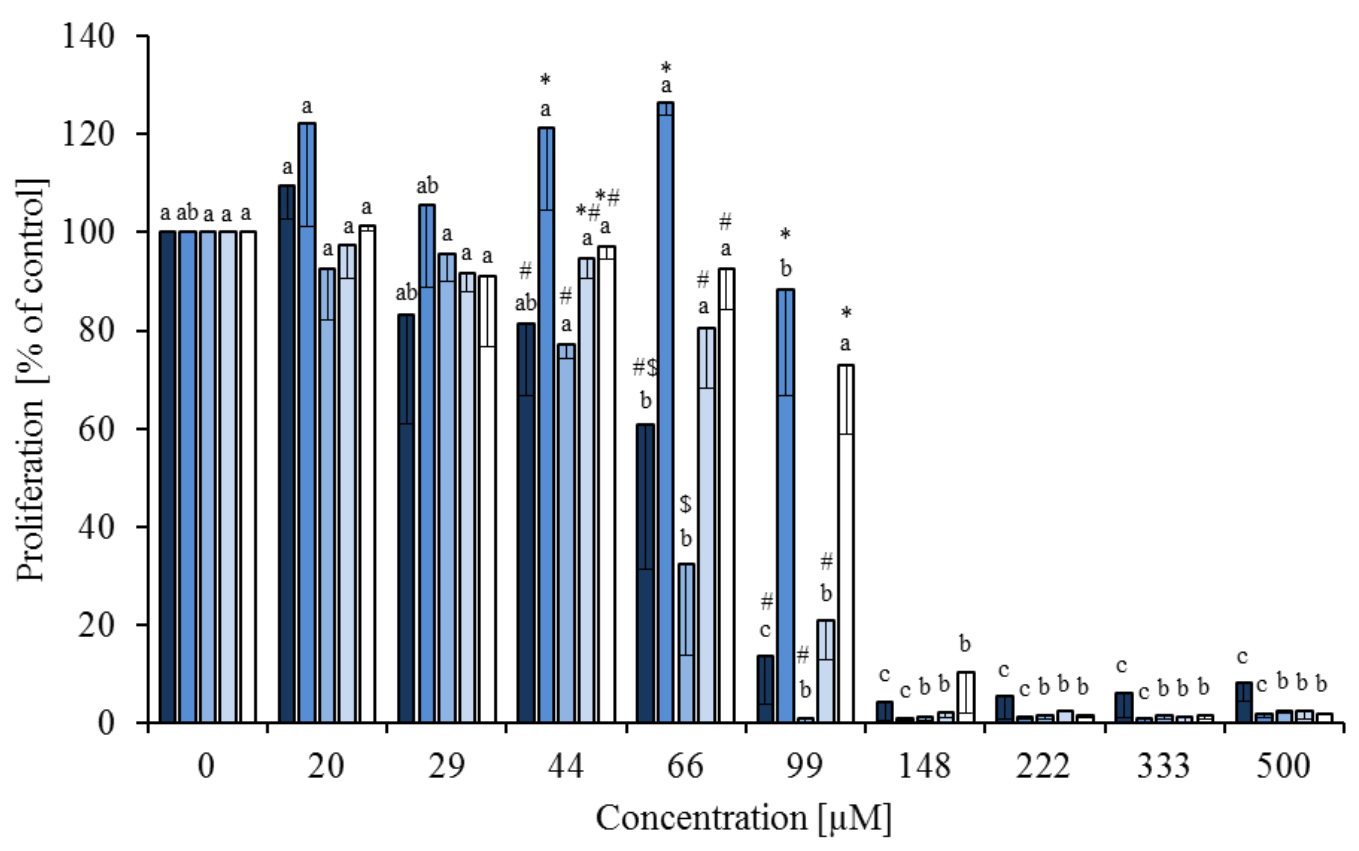

\subsection{Fatty Acid Combinations}

FA combinations were investigated at different concentrations (0, 33, 66, 99 and $500 \mu \mathrm{M}): 60 \%$ of the FA mixture and $40 \%$ cis-9,trans-11 CLA or trans-10,cis-12 CLA or LA or a mixture of these 3 C18:2 FA (13.3\% of each FA). There was no effect of FA combination $(p=0.977)$ and no interaction between FA combination and concentration $(p=0.987)$. Rising concentrations of the FA significantly inhibited PBMC proliferation ( $p<0.01$, Figure 3$)$. 
Figure 3. Effects of the combination of the fatty acid mixture* $(60 \%)$ with either $40 \%$

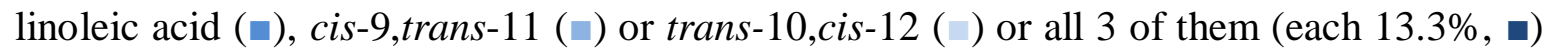
on concanavalin A stimulated proliferation of bovine peripheral blood mononuclear cells (PBMC) $(n=3)$ in the alamar blue assay (means \pm standard deviation). * containing $29.8 \%$ palmitic acid, $6.7 \%$ palmitoleic acid, $17.4 \%$ stearic acid and $46.1 \%$ oleic acid according to Rukkwamsuk et al. [22]. Med-Con = PBMC incubated without fatty acids and DMSO. a-c: different letters indicate significant differences within the same fatty acid, $p<0.05$, Tukey test.

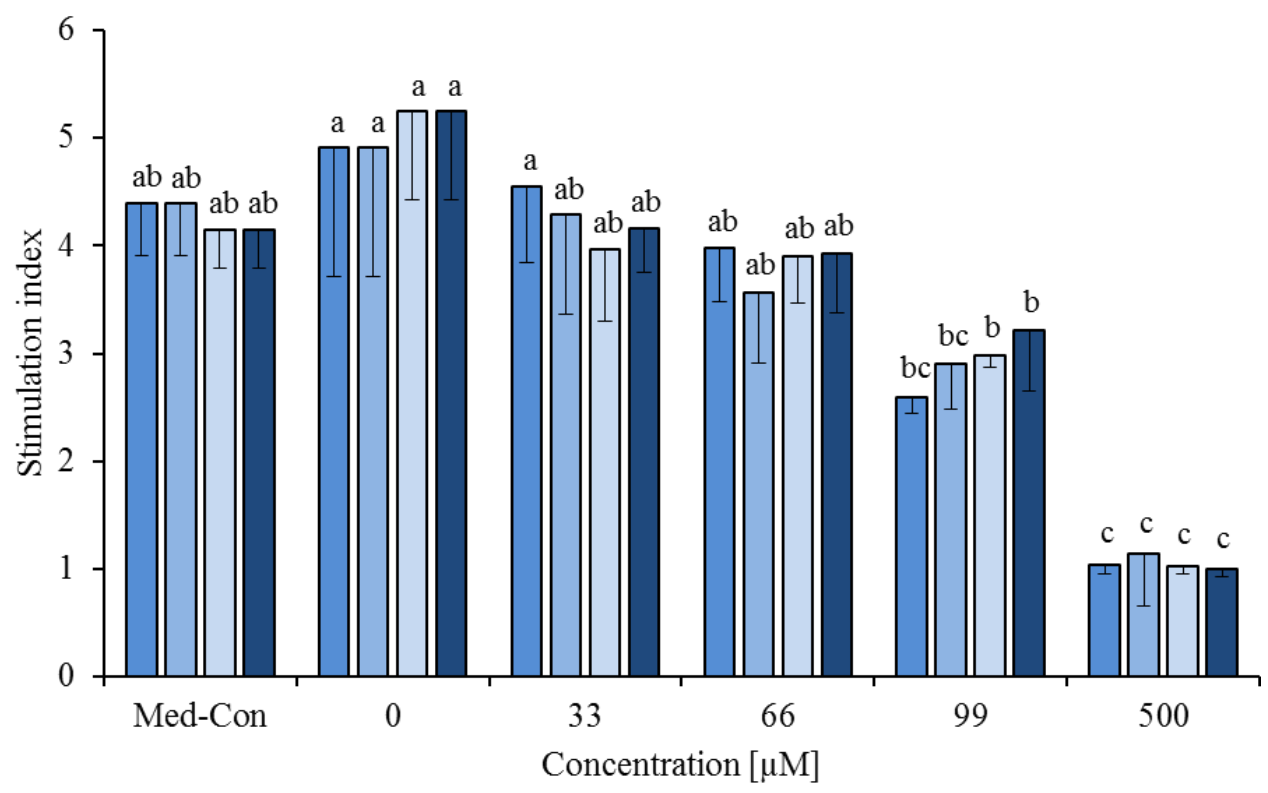

Figure 4. Effects of the combination of the fatty acid mixture* (60\%) with either phytanic acid $(40 \%, \square)$ or phytanic acid (20\%) and cis-9,trans-11 (20\%, $\square)$ or phytanic acid (20\%) and trans-10,cis-12 (20\%, ) on concanavalin A stimulated proliferation of bovine peripheral blood mononuclear cells (PBMC) $(n=3)$ in the alamar blue assay (means \pm standard deviation). * containing 29.8\% palmitic acid, 6.7\% palmitoleic acid, $17.4 \%$ stearic acid and $46.1 \%$ oleic acid according to Rukkwamsuk et al. [22]. Med-Con = PBMC incubated without fatty acids and DMSO. $a-c$ : different letters indicate significant differences within the same fatty acid, $p<0.05$, Tukey test.

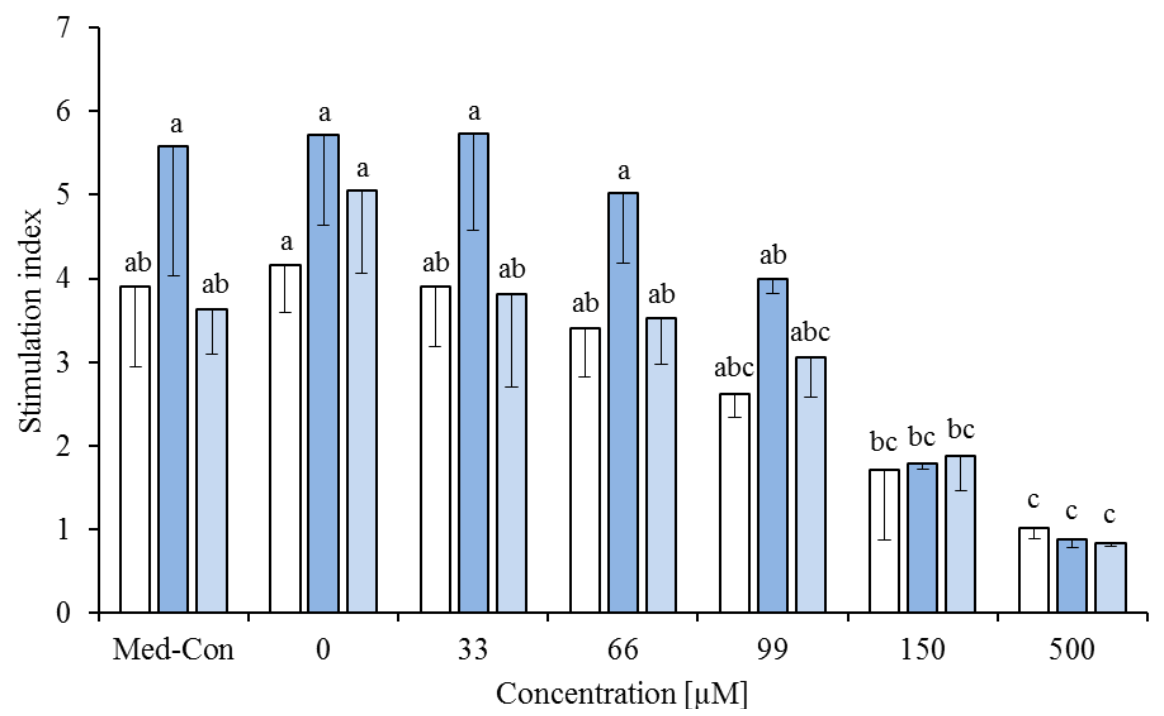


The FA mixture was also tested in combination with PA (60\% FA mixture and 40\% PA) and with PA and CLA (60\% FA mixture, 20\% PA and 20\% cis-9,trans-11 and 60\% FA mixture, 20\% PA and $20 \%$ trans-10,cis-12) at $0,33,66,99,150$ and $500 \mu \mathrm{M}$. There was an effect of FA combination $(p<0.01)$ and FA concentration $(p<0.01)$, but no interaction between FA combination and concentration ( $p=0.225$, Figure 4$)$.

\subsection{Cytokine and PPAR- $\gamma$ mRNA Expression}

The cis-9,trans-11 CLA isomer and LA were chosen for cytokine and PPAR- $\gamma$ expression analyses, because their $\mathrm{IC}_{50}$ values showed the greatest difference in proliferation (based on results obtained with the $\mathrm{AB}$ assay). Therefore, PBMC were incubated with the concentration of the $\mathrm{IC}_{50}$ value of the investigated FA and $77 \mu \mathrm{M}$, which is the mean concentration of the $\mathrm{IC}_{50}$ values of cis-9,trans-11 and LA. Furthermore, the cells were incubated with medium (Med-Con) or DMSO (DMSO-Con) in the concentration used to dissolve the FA. The expression was analyzed in non-stimulated and ConA-stimulated cells and the results are presented in Table 2.

Table 2. Expression of cytokine and PPAR- $\gamma$ mRNA. Unstimulated (-) and concanavalin A (ConA) stimulated $(+)$ bovine peripheral blood mononuclear cells were incubated with DMSO (0.2\%), medium (without DMSO or fatty acids), $100.7 \mu \mathrm{M}$ linoleic acid ( $\mathrm{IC}_{50} \mathrm{LA}$ ), $77 \mu \mathrm{M}$ linoleic acid (77 $\mu \mathrm{M}$ LA), $53.8 \mu \mathrm{M}$ cis-9,trans-11 ( IC $_{50}$ cis-9,trans-11), $77 \mu \mathrm{M}$ cis-9,trans-11 (77 $\mu \mathrm{M}$ cis-9,trans-11). Means \pm standard deviation, $n=3$.

\begin{tabular}{|c|c|c|c|c|c|c|}
\hline Treatment & ConA & IL-4 & IL-10 & TNF- $\alpha$ & IFN- $\gamma$ & PPAR- $\gamma$ \\
\hline \multirow{2}{*}{ DMSO } & - & $26,852 \pm 3032$ & $6201 \pm 1083$ & $1039 \pm 419$ & $5181 \pm 5759$ & $4881 \pm 790$ \\
\hline & + & $22,984 \pm 4567$ & $3808 \pm 1765$ & $4969 \pm 1640$ & $109,082 \pm 56,582^{\text {a }}$ & $3514 \pm 1022^{a, b}$ \\
\hline \multirow{2}{*}{ Medium } & - & $28,825 \pm 5887$ & $6700 \pm 1848$ & $900 \pm 237$ & $3617 \pm 3273$ & $4978 \pm 565$ \\
\hline & + & $26,714 \pm 3416$ & $3719 \pm 827 *$ & $8509 \pm 4635 *$ & $295,989 \pm 167,635^{b, *}$ & $3907 \pm 694^{\mathrm{a}, \mathrm{b}}$ \\
\hline \multirow{2}{*}{$\mathrm{IC}_{50} \mathrm{LA}$} & - & $23,941 \pm 4335$ & $5312 \pm 994$ & $370 \pm 145$ & $613 \pm 570$ & $4019 \pm 739$ \\
\hline & + & $34,703 \pm 7345$ & $4146 \pm 1362$ & $10,194 \pm 5630 *$ & $242,302 \pm 126,184^{\mathrm{a}, \mathrm{b}, *}$ & $3454 \pm 365^{\mathrm{a}, \mathrm{b}}$ \\
\hline \multirow{2}{*}{$77 \mu \mathrm{M}$ LA } & - & $25,845 \pm 1695$ & $5635 \pm 401$ & $506 \pm 179$ & $1809 \pm 1570$ & $4547 \pm 467$ \\
\hline & + & $28,348 \pm 15,180$ & $3520 \pm 1019$ & $9683 \pm 7214$ & $204,490 \pm 159,761^{\mathrm{a}, \mathrm{b}}$ & $2820 \pm 635^{a}$ \\
\hline $\mathrm{IC}_{50}$ & - & $32,230 \pm 4300$ & $7245 \pm 866$ & $588 \pm 87$ & $743 \pm 648$ & $5507 \pm 1203$ \\
\hline cis-9,trans-11 & + & $32,640 \pm 1566$ & $5504 \pm 1085$ & $8957 \pm 4128$ & $97,534 \pm 16,261^{\mathrm{a}, \mathrm{b}}$ & $4641 \pm 859^{\mathrm{a}, \mathrm{b}}$ \\
\hline $77 \mu \mathrm{M}$ & - & $29,684 \pm 3774$ & $6917 \pm 617$ & $511 \pm 58$ & $430 \pm 319$ & $5254 \pm 712$ \\
\hline cis-9,trans-11 & + & $31,867 \pm 7269$ & $5252 \pm 349$ & $8046 \pm 4588$ & $68,327 \pm 28,935^{a}$ & $5288 \pm 439^{b}$ \\
\hline$p$-value & & 0.182 & $<0.001$ & $<0.001$ & $<0.001$ & $<0.001$ \\
\hline
\end{tabular}

There were no treatment effects (FA and ConA stimulation) for IL-4. The expression of IL-10 was higher in non-stimulated PBMC than in ConA-stimulated PBMC, which was significant for the Med-Con. TNF- $\alpha$ was more expressed in ConA-stimulated PBMC. Significant differences occurred for the Med-Con and the IC $_{50}$ of LA. In addition, the mRNA expression of IFN- $\gamma$ was induced by ConA stimulation, which also resulted in significant differences for the Med-Con and the $\mathrm{IC}_{50}$ of LA. Within the ConA-stimulated PBMC the expression of IFN- $\gamma$ was decreased in DMSO-Control and $77 \mu \mathrm{M}$ 
cis-9,trans-11 compared to Med-Con. There were no differences of PPAR- $\gamma$ expression between non-stimulated and ConA-stimulated PBMC, but the expression was significantly higher in the ConA-stimulated PBMC treated with $77 \mu \mathrm{M}$ cis-9,trans-11 than that treated with $77 \mu \mathrm{M}$ LA. IL-12 was not expressed in samples from non-stimulated cells and only weakly in some samples from ConA-stimulated cells (results not shown).

\section{Discussion}

Around parturition the dairy cow is susceptible to infectious diseases like mastitis and experiences a state of immunosuppression [28]. Increased NEFA concentrations are discussed as a reason for this immunosuppression [29,30]. Due to the demands of the fetus in late pregnancy and the beginning of lactation, the energy requirements increase in this transition period while the dry matter intake is reduced [31]. Therefore, the cow mobilizes body fat from adipose tissue as an additional source of energy [32]. This lipomobilization has the effect that the concentration of NEFA and also of $\beta$-hydroxybutyrate increases in plasma [32,33]. Hence, the composition of the FA mixture used in the present study is based on the FA composition of subcutaneous adipose tissue [22] in order to mimic the lipomobilization and the situation in vivo.

For the dose response studies on cell proliferation, two different assays were used for evaluation: $\mathrm{AB}$ and BrdU assay. The BrdU assay actually measures newly synthesized DNA, whereas the AB assay evaluates the metabolic activity of living cells [21,34]. Both assays showed similar results and the calculated $\mathrm{IC}_{50}$ values are in the same range for the FA mixture, LA and cis-9,trans-11. For trans-10,cis-12 and PA the differences in the $\mathrm{IC}_{50}$ values were slightly greater. In the BrdU assay the signal of non-stimulated cells was weak, as obviously the non-stimulated cells did not proliferate, so no SI was calculated. In the $\mathrm{AB}$ assay, more differences were observed between the FA (in the concentration range from 20 to $148 \mu \mathrm{M}$ ), than in the BrdU assay, where significant differences between FA occurred in concentrations from 44 to $99 \mu \mathrm{M}$.

In the present study, the FA mixture inhibited the mitogen-stimulated proliferation of PBMC with an $\mathrm{IC}_{50}$ value of $80.8 \mu \mathrm{M}$. These concentrations are much lower than results from another study that investigated different NEFA concentrations on the proliferation of bovine PBMC [29]. In that study, the proliferation was only decreased at 1000 and $2000 \mu \mathrm{M}$ in response to phythemagglutinin (PHA) and ConA, and in addition at $500 \mu \mathrm{M}$ in response to pokeweed mitogen (PWM). The composition of the NEFA was slightly different. It contained 5\% LA, which was not in the FA mixture of the present study, because LA was tested separately. LA increased the ConA-stimulated proliferation of PBMC in the present study. This was observed in comparison to the control and to the other investigated FA up to $99 \mu \mathrm{M}$. Stimulating effects of LA on bovine PBMC were also found by Lacetera et al. [35] where the proliferation (BrdU assay) was increased at $9 \mu \mathrm{M}$ LA in response to PWM, and Thanasak et al. [36]. In that study, LA increased the proliferation at 5 and $25 \mu \mathrm{M}$ LA (without using a mitogen). At higher concentrations LA had inhibiting effects on the proliferation of PBMC which was seen in the present study (IC50 value $100.7 \mu \mathrm{M}$ ), by Lacetera et al. [35] (reduced proliferation at $103 \mu \mathrm{M}$ in response to ConA and PWM) and Thanasak et al. [36] (reduced proliferation at 125 and $250 \mu \mathrm{M}$ in response to ConA). In ewes the proliferation of PBMC was not affected by LA up to $100 \mu \mathrm{M}$ [37]. 
The effects of CLA on cell proliferation in vitro have been predominantly investigated on various tumor/cancer cell lines, with inhibiting effects, e.g., on the mammary tumor cell line MDA-MB-231 [38], Jurkat cells [39] and human hepatoma HepG2 cells [40]. In a study using non tumor cells, only the trans-9,trans-11 CLA isomer $(5-60 \mu \mathrm{M})$ inhibited the proliferation of bovine aortic endothelial cells. Other CLA isomers (cis-9,trans-11; cis-9,cis-11; trans-10,cis-12 and cis-11,trans-13) had no effect on proliferation of these cells [41]. In the present investigation the inhibiting effect of cis-9,trans-11 was observed at lower concentrations than for the trans-10,cis-12 isomer in both assays. However, these differences did not induce significantly different $\mathrm{IC}_{50}$ values of the 2 isomers. Although differences occurred between LA and the CLA isomers cis-9,trans-11 and trans-10,cis-12, these differences were not found when these FA were combined with the FA mixture. The combinations of different FA reflect the situation in the organism better than the single FA and the concentrations used in the study mimic the NEFA concentrations found in healthy cows [29]. Furthermore, CLA supplements used for in vivo studies mostly contain a mixture of CLA isomers. The supplementation of dairy cows with a CLA supplement containing mainly cis-9,trans-11 and trans-10,cis-12 CLA did not alter the mitogen-stimulated proliferation of PBMC ex vivo [7,8], but the SI of splenocytes was decreased in the CLA group after $105 \mathrm{~d}$ of supplementation [8].

PA has potential bioactive effects and is discussed in the context of type-2 diabetes [9]. It is reported that PA decreases the proliferation of human prostate cancer cells PC-3 (50 $\mu \mathrm{M})$ [42], although a positive correlation between prostate cancer and serum PA levels was found [43]. The effects of PA on immune cells have, to the authors' knowledge, not yet been investigated. The results of the present study show that PA reduces the proliferation of bovine PBMC beginning at a concentration of $148 \mu \mathrm{M}$ and the calculated $\mathrm{IC}_{50}$ value was at $94.7 \mu \mathrm{M}$. Avigan [12] indicated the concentration of PA in bovine serum with $5.9 \mathrm{mg} / 100 \mathrm{~mL}(=188.8 \mu \mathrm{M})$ without further information about the investigated animals. Thompson et al. [13] analyzed the concentration of PA in triglycerides of arterial and mammary venous plasma, obtaining much lower concentrations (arterial plasma $6.2 \mu \mathrm{M}$, venous plasma $6.0 \mu \mathrm{M}$ ). As seen for the other investigated FA PA inhibited the ConA-stimulated proliferation of bovine PBMC dose-dependently. Only in the concentration range of 66 to $99 \mu \mathrm{M}$ differences to the cis-9,trans-11 and trans-10,cis-12 CLA isomer occurred. It was hypothesized that there might be complementary effects of PA and CLA in their anti-diabetic activity [19]. Therefore, a combination of the FA mixture with PA and the CLA isomers cis-9,trans-11 and trans-10,cis-12 was tested to investigate complementary effects on PBMC. No differences in the SI were found between the tested FA combinations at the corresponding concentrations. Hence, no complementary effects of PA and CLA were observed on bovine PBMC.

Based on the results from the dose response studies, and the combinations of C18:2 FA with the FA mixture, cytokine expression analyses were performed in selected treatments. Because no differences occurred within the FA combinations, the pure FA were chosen for the analyses. The greatest difference in IC $_{50}$ values was between cis-9,trans-11 CLA and LA, so these two FA were used. The expression of IL-4, IL-10, IL-12, TNF- $\alpha$ and IFN- $\gamma$ was analyzed in non-stimulated PBMC and in response to ConA. ConA did not increase the expression of IL-4 and IL-10. Furthermore, the expression of IL-10 was significantly increased in PBMC cultured in medium without the addition of the FA or the vehicle control DMSO in non-stimulated cells compared to ConA-stimulated cells. In human PBMC the expression of IL-4 was only slightly increased by 2 mitogens (PHA and phorbol 
myristate acetate [PMA]) after 4 and 24 h, respectively [44]. Wattegedera et al.[45] examined the expression of IL-10 and IFN- $\gamma$ from ovine PBMC in response to ConA over $96 \mathrm{~h}$. The expression of IFN- $\gamma$ was higher than that of IL-10, which is in line with the present results. In contrast, ConA increased the expression of IL-10 in ovine PBMC, whereas ConA-stimulation did not increase its expression in bovine PBMC in the present study. The expression of TNF- $\alpha$ in non-stimulated PBMC might be due to compounds of the FBS in the culture medium. One of these compounds is bovine serum albumin which increased TNF- $\alpha$ production in murine macrophages [46].

TNF- $\alpha$ expression was not altered by cis-9,trans-11 or LA in PBMC incubated with or without ConA in the present study. Ex vivo the basal expression of TNF- $\alpha$ from bovine PBMC and splenocytes was not affected by CLA supplementation [8], which is in line with the present results. The cis-9,trans-11 isomer and LA had no effect on the production of TNF- $\alpha$ in whole blood cultures from Holstein heifers stimulated with LPS, but the TNF- $\alpha$ production was decreased when cells were incubated in the presence of 50 or $100 \mu \mathrm{M}$ trans-10,cis-12 CLA [47]. LPS is a major component of the outer membrane of gram negative bacteria that interacts with specific receptors and induces the release of inflammastory mediators [48]. In PBMC from pigs the LPS-stimulated expression of TNF- $\alpha$ was decreased in vitro by the trans-10,cis-12 isomer [49,50]. In contrast, TNF- $\alpha$ increased in the study of Kim et al. [50] when non-stimulated cells were incubated with trans-10,cis-12 (10 $\mu \mathrm{M})$. The cis-9,trans-11 isomer or a mix of cis-9,trans-11 and trans-10,cis-12 (final concentration $100 \mu \mathrm{M}$ ) had no effect on TNF- $\alpha$ mRNA expression of LPS-stimulated porcine PBMC [49]. The anti-inflammatory effects were confirmed in vivo in LPS-challenged pigs who received a diet containing $2 \%$ CLA. The expression of TNF- $\alpha$ and IL-6, which is also an inflammatory cytokine, was decreased in thymus and spleen and furthermore, the anti-inflammatory cytokine IL-10 was increased [49]. IL-10 expression and production was also increased in LPS-stimulated dendritic cells from mice in response to cis-9,trans-11 (50 $\mu \mathrm{M})$ in vitro, whereas IL-12 was decreased [51]. In the present study there were no differences in IL-10 and IL-4 expression due to FA treatment. The expression of Il-4 in bovine splenocytes was increased after 42 days of supplementation compared to an initial group not supplemented with CLA, but there was no effect on expression in PBMC and the expression of IL-10 in both cell types [8].

Significant effects were observed in the expression of IFN- $\gamma$. The expression was decreased in ConA-stimulated cells treated with $77 \mu \mathrm{M}$ cis-9,trans-11 and the vehicle control DMSO compared to the medium control. Treatment with the $\mathrm{IC}_{50}$ value of cis-9,trans-11 decreased the expression of IFN- $\gamma$ only numerically compared to the medium control. It is questionable, if the decrease of IFN- $\gamma$ mRNA expression is due to the treatment with cis-9,trans-11 or an effect of DMSO which served as an solvent for the FA. The expression of IFN- $\gamma$ increased after 105 days of supplementation in bovine PBMC and splenocytes compared to a non-supplemented initial group and 42 days of CLA supplementation [8]. The expression of IFN- $\gamma$ and IL- 6 in bursa tissue of chicken infected with the infectious bursal disease virus (IBDV) did not increase in CLA-fed birds as much as in control animals 3 days post infection [52].

The expression of PPAR- $\gamma$ was significantly lower in ConA-stimulated PBMC when cells were treated with $77 \mu \mathrm{M}$ LA than with $77 \mu \mathrm{M}$ cis-9,trans-11. However, there were no differences between the other tested FA concentrations or controls, so there is no clear effect of enhanced PPAR- $\gamma$ expression due to cis-9,trans-11 in bovine PBMC. The PPAR- $\gamma$ antagonist GW9662 did not reverse the inhibiting effects of cis-9,trans-11 (25 and $50 \mu \mathrm{M})$ on proliferation of bovine PBMC [53]. Hence, 
the authors concluded, that the inhibition of proliferation of bovine PBMC by cis-9,trans-11 CLA is independent from PPAR- $\gamma$. Enhanced expression of PPAR- $\gamma$ in response to the trans-10,cis-12 isomer was found in porcine PBMC in vitro [50,54]. In the latter study Kim et al. [50] concluded that the immunostimulating effects (increased NFאB activity and expression of TNF- $\alpha$ in non-stimulated PBMC) and anti-inflammatory effects (decreased NFKB activity and TNF- $\alpha$ expression in LPS-stimulated PBMC) are PPAR- $\gamma$ dependent. In bovine immune cells the LPS induced production of TNF- $\alpha$ is attenuated by a PPAR- $\gamma$ agonist [47]. The observations argue for isomer specific effects on PPAR- $\gamma$ expression in PBMC. Isomer specific effects were also found in human preadipocytes, where the cis-9,trans-11 isomer increased the expression of PPAR- $\gamma$ target genes. In contrast, the trans-10,cis-12 isomer decreased the expression of PPAR- $\gamma$ [55].

\section{Conclusions}

FA inhibit the ConA-stimulated proliferation of bovine PBMC in vitro in a dose dependent manner. Differences in the inhibition were only seen when single FA were tested but not in combination. Especially the effects in response to LA were different from the other investigated FA. The $\mathrm{IC}_{50}$ value of PA did not differ from that of the CLA isomers cis-9,trans-11 and trans-10,cis-12.

The effect of the cis-9,trans-11 CLA isomer on cytokine expression was marginal and does not indicate inflammatory or anti-inflammatory effects of CLA on bovine PBMC in vitro.

\section{Acknowledgments}

The authors would like to thank the Deutsche Forschungsgemeinschaft, who financially supported the work (PAK 286/1, DA558/5-1, WP 7).

\section{Conflict of Interest}

The authors declare no conflict of interest.

\section{References}

1. Kepler, C.R.; Hirons, K.P.; McNeill, J.J.; Tove, S.B. Intermediates and products of the biohydrogenation of linoleic acid by Butyrinvibrio fibrisolvens. J. Biol. Chem. 1966, 241, 1350-1354.

2. Fritsche, J.; Steinhart, H. Amounts of conjugated linoleic acid (CLA) in German foods and evaluation of daily intake. Z. Lebensm. Unters. F. A 1998, 206, 77-82.

3. Kay, J.K.; Roche, J.R.; Kolver, E.S.; Thomson, N.A.; Baumgard, L.H. A comparison between feeding systems (pasture and TMR) and the effect of vitamin E supplementation on plasma and milk fatty acid profiles in dairy cows. J. Dairy Res. 2005, 72, 322-332.

4. Griinari, J.M.; Corl, B.A.; Lacy, S.H.; Chouinard, P.Y.; Nurmela, K.V.; Bauman, D.E. Conjugated linoleic acid is synthesized endogenously in lactating dairy cows by Delta(9)-desaturase. J. Nutr. 2000, 130, 2285-2291. 
5. Turpeinen, A.M.; Mutanen, M.; Aro, A.; Salminen, I.; Basu, S.; Palmquist, D.L.; Griinari, J.M. Bioconversion of vaccenic acid to conjugated linoleic acid in humans. Am. J. Clin. Nutr. 2002, 76, 504-510.

6. Baumgard, L.H.; Corl, B.A.; Dwyer, D.A.; Saebo, A.; Bauman, D.E. Identification of the conjugated linoleic acid isomer that inhibits milk fat synthesis. Am. J. Physiol. 2000, 278, R179-R184.

7. Renner, L.; Pappritz, J.; Kramer, R.; Döll, S.; Jahreis, G.; Dänicke, S. Fatty acid profile and proliferation of bovine blood mononuclear cells after conjugated linoleic acid supplementation. Lipids Health Dis. 2012, 11, 63.

8. Renner, L.; von Soosten, D.; Sipka, A.; Döll, S.; Beineke, A.; Schuberth, H.J.; Dänicke, S. Effect of trans-10,cis-12 and cis-9,trans-11 conjugated linoleic acid (CLA) on proliferation and cytokine expression of bovine PBMC and splenocytes ex vivo. Arch. Anim. Nutr. 2012, 66, 73-85.

9. Hellgren, L.I. Phytanic acid-An overlooked bioactive fatty acid in dairy fat? Ann. N. Y. Acad. Sci. 2010, 1190, 42-49.

10. Verhoeven, N.M.; Jakobs, C. Human metabolism of phytanic acid and pristanic acid. Prog. Lipid Res. 2001, 40, 453-466.

11. Patton, S.; Benson, A.A. Phytol metabolism in the bovine. Biochim. Biophys. Acta 1966, 125, $22-32$.

12. Avigan, J. The presence of phytanic acid in normal human and animal plasma. Biochim. Biophys. Acta 1966, 116, 391-394.

13. Thompson, G.E.; Christie, W.W. Extraction of plasma triacylglycerols by the mammary gland of the lactating cow. J. Dairy Res. 1991, 58, 251-255.

14. Price, A.J.; Allen, N.E.; Appleby, P.N.; Crowe, F.L.; Jenab, M.; Rinaldi, S.; Slimani, N.; Kaaks, R.; Rohrmann, S.; Boeing, H.; et al. Plasma phytanic acid concentration and risk of prostate cancer: Results from the European Prospective Investigation into Cancer and Nutrition. Am. J. Clin. Nutr. 2010, 91, 1769-1776.

15. Wanders, R.J.A.; Komen, J.; Ferdinandusse, S. Phytanic acid metabolism in health and disease. Biochim. Biophys. Acta 2011, 1811, 498-507.

16. Kitareewan, S.; Burka, L.T.; Tomer, K.B.; Parker, C.E.; Deterding, L.J.; Stevens, R.D.; Forman, B.M.; Mais, D.E.; Heyman, R.A.; McMorris, T.; et al. Phytol metabolites are circulating dietary factors that activate the nuclear receptor RXR. Mol. Biol. Cell 1996, 7, 1153-1166.

17. Ellinghaus, P.; Wolfrum, C.; Assmann, G.; Spener, F.; Seedorf, U. Phytanic acid activates the peroxisome proliferator-activated receptor $\alpha(\mathrm{PPAR} \alpha)$ in sterol carrier protein 2-/sterol carrier protein X-deficient mice. J. Biol. Chem. 1999, 274, 2766-2772.

18. Moya-Camarena, S.Y.; Vanden Heuvel, J.P.; Blanchard, S.G.; Leesnitzer, L.A.; Belury, M.A. Conjugated linoleic acid is a potent naturally occurring ligand and activator of PPAR alpha. J. Lipid Res. 1999, 40, 1426-1433.

19. McCarty, M.F. The chlorophyll metabolite phytanic acid is a natural rexinoid-Potential for treatment and prevention of diabetes. Med. Hypotheses 2001, 56, 217-219.

20. Renner, L.; Schwabe, A.; Döll, S.; Höltershinken, M.; Dänicke, S. Effect of rare earth elements on beef cattle growth performance, blood clinical chemical parameters and mitogen stimulated proliferation of bovine peripheral blood mononuclear cells in vitro and ex vivo. Toxicol. Lett. 2011, 201, 277-284. 
21. O’Brien, J.; Wilson, I.; Orton, T.; Pognan, F. Investigation of the Alamar Blue (resazurin) fluorescent dye for the assessment of mammalian cell cytotoxicity. Eur. J. Biochem. 2000, 267, 5421-5426.

22. Rukkwamsuk, T.; Geelen, M.J.H.; Kruip, T.A.M.; Wensing, T. Interrelation of fatty acid composition in adipose tissue, serum, and liver of dairy cows during the development of fatty liver postpartum. J. Dairy Sci. 2000, 83, 52-59.

23. Goyarts, T.; Dänicke, S.; Grove, N.; Tiemann, U.; Rothkötter, H.J. Methodical aspects of in vitro proliferation of porcine blood lymphocytes when exposed to deoxynivalenol (DON). Landbauforsch. Völk. 2006, 56, 139-148.

24. Almeida, P.E.; Weber, P.S.D.; Burton, J.L.; Tempelman, R.J.; Steibel, J.P.; Zanella, A.J. Gene expression profiling of peripheral mononuclear cells in lame dairy cows with foot lesions. Vet. Immunol. Immunopathol. 2007, 120, 234-245.

25. Neuvians, T.P.; Schams, D.; Berisha, B.; Pfaffl, M.W. Involvement of pro-inflammatory cytokines, mediators of inflammation, and basic fibroblast growth factor in prostaglandin F-2 alpha-induced luteolysis in bovine corpus luteum. Biol. Reprod. 2004, 70, 473-480.

26. Yang, W.; Zerbe, H.; Petzl, W.; Brunner, R.M.; Günther, J.; Draing, C.; von Aulock, S.; Schuberth, H.-J.; Seyfert, H.-M. Bovine TLR2 and TLR4 properly transduce signals from

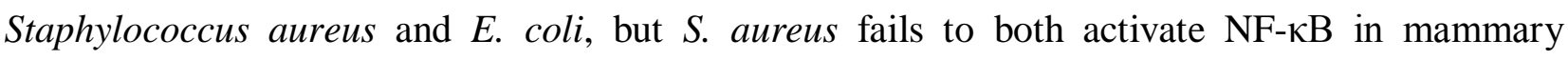
epithelial cells and to quickly induce TNF $\alpha$ and interleukin-8 (CXCL8) expression in the udder. Mol. Immunol. 2008, 45, 1385-1397.

27. Mercer, L.P.; Dodds, S.J.; Smith, D.L. New method for formulation of amino acid concentrations and ratios in diets of rats. J. Nutr. 1987, 117, 1936-1944.

28. Kehrli, M.E.; Harp, J.A. Immunity in the mammary gland. Vet. Clin. N. Am. 2001, 17, 495-516.

29. Lacetera, N.; Scalia, D.; Franci, O.; Bernabucci, U.; Ronchi, B.; Nardone, A. Short communication: Effects of nonesterified fatty acids on lymphocyte function in dairy heifers. J. Dairy Sci. 2004, 87, 1012-1014.

30. Ster, C.; Loiselle, M.C.; Lacasse, P. Effect of postcalving serum nonesterified fatty acids concentration on the functionality of bovine immune cells. J. Dairy Sci. 2012, 95, 708-717.

31. Grummer, R.R.; Mashek, D.G.; Hayirli, A. Dry matter intake and energy balance in the transition period. Vet. Clin. N. Am. 2004, 20, 447-470.

32. Goff, J.P.; Horst, R.L. Physiological changes at parturition and their relationship to metabolic disorders. J. Dairy Sci. 1997, 80, 1260-1268.

33. Contreras, G.A.; Sordillo, L.M. Lipid mobilization and inflammatory responses during the transition period of dairy cows. Comp. Immunol. Microb. Infect. Dis. 2011, 34, 281-289.

34. Gonzalez, R.J.; Tarloff, J.B. Evaluation of hepatic subcellular fractions for Alamar blue and MTT reductase activity. Toxicol. In Vitro 2001, 15, 257-259.

35. Lacetera, N.; Kuzminsky, G.; Morera, R.; Basirico, L. Fatty acids affect proliferation of peripheral blood mononuclear cells in dairy cows. Ital. J. Anim. Sci. 2007, 6, 434-436.

36. Thanasak, J.; Muller, K.E.; Dieleman, S.J.; Hoek, A.; Noordhuizen, J.P.; Rutten, V.P. Effects of polyunsaturated fatty acids on the proliferation of mitogen stimulated bovine peripheral blood mononuclear cells. Vet. Immunol. Immunopathol. 2005, 104, 289-295. 
37. Lacetera, N.; Franci, O.; Scalia, D.; Bernabucci, U.; Ronchi, B.; Nardone, A. Effects on functions of ovine blood mononuclear cells for each of several fatty acids at concentrations found in plasma of healthy and ketotic ewes. Am. J. Vet. Res. 2002, 63, 958-962.

38. Ma, D.W.L.; Field, C.J.; Clandinin, M.T. An enriched mixture of trans-10,cis-12-CLA inhibits linoleic acid metabolism and PGE2 synthesis in MDA-MB-231 cells. Nutr. Cancer 2002, 44, 203-212.

39. Luongo, D.; Bergamo, P.; Rossi, M. Effects of conjugated linoleic acid on growth and cytokine expression in Jurkat T cells. Immunol. Lett. 2003, 90, 195-201.

40. Igarashi, M.; Miyazawa, T. The growth inhibitory effect of conjugated linoleic acid on a human hepatoma cell line, HepG2, is induced by a change in fatty acid metabolism, but not the facilitation of lipid peroxidation in the cells. Biochim. Biophys. Acta Mol. Cell Biol. Lipids 2001, 1530, 162-171.

41. Lai, K.L.; Torres-Duarte, A.P.; Vanderhoek, J.Y. 9-trans,11-trans-CLA: Antiproliferative and proapoptotic effects on bovine endothelial cells. Lipids 2005, 40, 1107-1116.

42. Tang, X.H.; Suh, M.J.; Li, R.; Gudas, L.J. Cell proliferation inhibition and alterations in retinol esterification induced by phytanic acid and docosahexaenoic acid. J. Lipid Res. 2007, 48, 165-176.

43. Xu, J.; Thornburg, T.; Turner, A.R.; Vitolins, M.; Case, D.; Shadle, J.; Hinson, L.; Sun, J.; Liu, W.; Chang, B.; et al. Serum levels of phytanic acid are associated with prostate cancer risk. Prostate 2005, 63, 209-214.

44. Sullivan, K.E.; Cutilli, J.; Piliero, L.M.; Ghavimi-Alagha, D.; Starr, S.E.; Campbell, D.E.; Douglas, S.D. Measurement of cytokine secretion, intracellular protein expression, and mRNA in resting and stimulated peripheral blood mononuclear cells. Clin. Diagn. Lab. Immunol. 2000, 7 , 920-924.

45. Wattegedera, S.R.; Watson, D.M.; Hope, J.C.; Kaiser, P.; Sales, J.; McInnes, C.J.; Entrican, G. Relative quantitative kinetics of interferon-gamma and interleukin-10 mRNA and protein production by activated ovine peripheral blood mononuclear cells. Vet. Immunol. Immunopathol. 2010, 136, 34-42.

46. Zheng, Z.M.; Specter, S.C.; Lancz, G. Bovine serum albumin preparations enhance in vitro production of tumor necrosis factor alpha by murine macrophages. Immunol. Investig. 1995, 24, 737-756.

47. Perdomo, M.C.; Santos, J.E.; Badinga, L. Trans-10,cis-12 conjugated linoleic acid and the PPAR- $\gamma$ agonist rosiglitazone attenuate lipopolysaccharide-induced TNF- $\alpha$ production by bovine immune cells. Domest. Anim. Endocrinol. 2011, 41, 118-125.

48. Aderem, A.; Ulevitch, R.J. Toll-like receptors in the induction of the innate immune response. Nature 2000, 406, 782-787.

49. Changhua, L.; Jindong, Y.; Defa, L.; Lidan, Z.; Shiyan, Q.; Jianjun, X. Conjugated linoleic acid attenuates the production and gene expression of proinflammatory cytokines in weaned pigs challenged with lipopolysaccharide. J. Nutr. 2005, 135, 239-244.

50. Kim, D.I.; Kim, K.H.; Kang, J.H.; Jung, E.M.; Kim, S.S.; Jeung, E.B.; Yang, M.P. Trans-10,cis12-conjugated linoleic acid modulates NF- $\kappa \mathrm{B}$ activation and TNF- $\alpha$ production in porcine peripheral blood mononuclear cells via a PPARgamma-dependent pathway. Br. J. Nutr. 2011, 105, 1329-1336. 
51. Loscher, C.E.; Draper, E.; Leavy, O.; Kelleher, D.; Mills, K.H.G.; Roche, H.M. Conjugated linoleic acid suppresses NF- $\mathrm{BB}$ activation and IL-12 production in dendritic cells through ERK-mediated IL-10 induction. J. Immunol. 2005, 175, 4990-4998.

52. Long, F.Y.; Guo, Y.M.; Wang, Z.; Liu, D.; Zhang, B.K.; Yang, X. Conjugated linoleic acids alleviate infectious bursal disease virus-induced immunosuppression in broiler chickens. Poult. Sci. 2011, 90, 1926-1933.

53. Hussen, J.; Schuberth, H.J. The Effect of 9-cis:11-trans Conjugated Linoleic Acid (CLA), 15d-PGJ2 and GW9662 on the Proliferation of Bovine Peripheral Blood Mononuclear Cells in vitro. In Proceedings of the 65th Conference of the Society of Nutrition Physiology, Göttingen, Germany, 15-17 March 2011; p. 97.

54. Kang, J.H.; Lee, G.S.; Jeung, E.B.; Yang, M.P. Trans-10,cis-12-conjugated linoleic acid increases phagocytosis of porcine peripheral blood polymorphonuclear cells in vitro. Br. J. Nutr. 2007, 97, 117-125.

55. Brown, J.M.; Boysen, M.S.; Jensen, S.S.; Morrison, R.F.; Storkson, J.; Lea-Currie, R.; Pariza, M.; Mandrup, S.; McIntosh, M.K. Isomer-specific regulation of metabolism and PPAR $\gamma$ signaling by CLA in human preadipocytes. J. Lipid Res. 2003, 44, 1287-1300.

(C) 2013 by the authors; licensee MDPI, Basel, Switzerland. This article is an open access article distributed under the terms and conditions of the Creative Commons Attribution license (http://creativecommons.org/licenses/by/3.0/). 